Article

\title{
Design and Thermal Characterization of Two Construction Solutions with and without Incorporation of Macroencapsulated PCM
}

\author{
António Figueiredo $^{1, *(\mathbb{D}}$, Filipe Rebelo ${ }^{1} \mathbb{D}$, António Samagaio $\left.{ }^{2} \mathbb{(}\right)$, Romeu Vicente ${ }^{1}\left(\mathbb{D}\right.$ and Jorge Lira ${ }^{3}$ \\ 1 RISCO-Research Centre for Risks and Sustainability in Construction, Civil Engineering Department, \\ University of Aveiro, 3810-193 Aveiro, Portugal; filiperebelo@ua.pt (F.R.); romvic@ua.pt (R.V.) \\ 2 Department of Environment and Planning, University of Aveiro, 3810-193 Aveiro, Portugal; samagaio@ua.pt \\ 3 SteelMe, Maia, 4475-830 Oporto, Portugal; jorge.lira@5dhome.pt \\ * Correspondence: ajfigueiredo@ua.pt
}

Citation: Figueiredo, A.; Rebelo, F.; Samagaio, A.; Vicente, R.; Lira, J. Design and Thermal Characterization of Two Construction Solutions with and without Incorporation of Macroencapsulated PCM. Infrastructures 2022, 7, 27. https:// doi.org/10.3390/infrastructures7030027 Academic Editor: Enrico Zacchei

Received: 21 January 2022

Accepted: 20 February 2022

Published: 22 February 2022

Publisher's Note: MDPI stays neutral with regard to jurisdictional claims in published maps and institutional affiliations.

Copyright: (C) 2022 by the authors. Licensee MDPI, Basel, Switzerland. This article is an open access article distributed under the terms and conditions of the Creative Commons Attribution (CC BY) license (https:/ / creativecommons.org/licenses/by/ $4.0 /)$.

\begin{abstract}
Improving the energy efficiency of new and existing building stock while fostering the use of renewable energy is one of the major goals of the Renovation Wave initiative promoted by the European Union. In this framework, the present research focuses on the design of an innovative and efficient construction solution for an external envelope and internal partitions that can improve energy efficiency and thermal comfort in lightweight construction technology for buildings. The use of phase change materials (PCMs), particularly in the macroencapsulated form, in building construction solutions or components enhances the buildings' thermal mass without significantly increasing the solutions' weight. Therefore, the solution herein developed is essentially targeted at lightweight building technology since the incorporation of a macroencapsulated PCM core will allow to store and release large amounts of energy per volume unit, in order to attenuate high indoor temperature fluctuations. In the scope of this study, the use of a thermally active core in a lightweight construction solution was designed and thermally characterized. Thus, an experimental campaign on the thermal properties of the solution containing macroencapsulated PCMs was performed, intended for applications in two twin full-scale cold-formed steel lightweight tiny houses. Regarding the hot box heat flux meter approach, the results revealed the following: good correlation between thermal conductivity and mean specimen temperatures for both construction assemblies tested, and significant thermal amplitude reduction with the use solution containing the macroencapsulated PCM core.
\end{abstract}

Keywords: thermal conductivity; phase change materials; energy efficiency; thermal energy storage; lightweight buildings

\section{Introduction}

The European Union policy framework for energy and environmental strategy focuses on the ambitious goal of reducing energy consumption and greenhouse gas emissions by improving buildings' energy efficiency, from new to existing building stock, assuring comfortable and healthier indoor environment conditions for the users [1,2]. Almeida et al. [3], achieved potential energy savings of $48 \%$ in terms of electricity consumption in the EU, revealing a potential improvement in the residential sector behavior, highlighting the importance of the rapid implementation of European regulations. Additionally, during the last decade, a noticeable trend to implement prefabricated and lightweight building components combined with a modular approach to construction has been observed. Despite lightweight construction typology representing an economic and ecological alternative to common building heavyweight solutions, it is also an excellent solution for retrofitting and refurbishment; however, it still presents challenging issues in terms of thermal performance, due to the lack of thermal mass and consequent reduced thermal inertia, a known drawback of this particular construction system. Thus, the present research is motivated 
by the pursuit of coupling the development of enhanced lightweight building assemblies: for future resilient and sustainable buildings to be energy efficient; to compensate for the reduced thermal inertia by using phase change materials (PCMs); and to mitigate the use of lightweight building technology in different climate contexts.

Innovative building solutions and components containing PCM have been the subject of numerous studies over the last years, highlighting the following: development of solutions for lightweight buildings [4-6]; PCM incorporation into mortars [7-9], bricks [10-12], and thermally activated concrete slabs [13,14]; gypsum plaster wallboards [15-17]; in panels for cooling purposes [18]; screed mortars [19,20]; microencapsulation and positioning into attic spaces [21]; and buildings' features optimization [4,5,22].

Despite the well-known advantages on the use of building components containing PCMs, several authors have reported important issues that must be considered regarding their use in buildings. Kuznik et al. [23] investigated the use of PCMs in a renovation project by comparing two rooms: one with wallboards containing PCMs, and the other with standard wallboards without PCM. The authors concluded that the use of PCMs increased the indoor thermal comfort in the room containing PCM wallboards; however, they also concluded that for several days, the latent heat storage capacity of the PCMs was not fully exploited due to its incomplete discharge overnight. Thus, a correct system design is mandatory, including the PCM operating temperature range as well as the positioning conditions where the PCM will be applied. Sun et al. [24] investigated the thermal performance of a room by simulating four different inorganic composite PCMs, which were simultaneously located into the wall air cavities and also combined with a double-layer of PCM into a radiant floor system. These combined PCM-containing solutions, leading to a reduction of $21.2 \%$ in the annual energy consumption. The authors also highlighted three parameters with extreme influence on the PCM efficiency and, consequently, on the building energy consumption: the thickness of the PCM layer; the thermal conductivity; and the relative position between the heat source and the PCM layers in the radiant floor systems. Thus, excessive layer thickness of PCM (and amount) as well as high values of thermal conductivity could lead to the worst results in terms of indoor thermal conditions, also leading to increased materials' costs during installation. Aligned with these issues, $\mathrm{Xu}$ et al. [25] highlighted that the PCM performance is affected by numerous factors, such as PCM layer thickness, melting range temperature, thermal conductivity, latent heat fusion, and the existence or absence of an air gap between the PCM and the covering layer. The authors concluded that the thickness of the PCM layer should not exceed $20 \mathrm{~mm}$ and the latent heat of fusion should be larger than $120 \mathrm{~kJ} \mathrm{~kg}^{-1}$ to be fully exploited.

Regarding the research concerning buildings with low thermal inertia, Kośny et al. [26] studied several possibilities to improve buildings' thermal behavior by applying solutions containing PCM. A total of five different solutions were investigated, including different types of insulation, position and thickness of the PCM layer, as well as type of PCM arrangement (condensed and dispersed). A time shift in peak temperatures was observed, shifting and reducing the number of operating hours of the air conditioning system, from daytime peak to night time. An inversion in the direction of the heat flow was also observed, allowing the use of passive cooling to the building. Thus, it is possible to acknowledge that the addition of PCM to the insulation layer translates to a substantial improvement in the thermal performance for this type of building. In this context, Rebelo et al. [8] presented a full thermophysical characterization of an innovative cementitious mortar incorporating microencapsulated PCMs, also targeted for low thermal mass buildings located in warm climates. The developed mortars are intended to be applied in contact with the insulation layer by the inner surface of the building envelope walls, aiming indoor passive thermal regulation toward mitigating the overheating phenomena in lightweight construction systems. Soares et al. [27] proposed the use of drywalls with phase change materials to overcome the low thermal inertia of LSF systems. This research work has the objective of optimizing 10 different factors with direct influence in the efficiency of the PCMdrywalls use. The authors concluded that the use of PCM-drywalls in LSF constructive 
systems allows to achieve a better building performance for all studied climates, with an optimum solution for each climate. In a review regarding the energy efficiency and thermal performance of LSF construction, Soares et al. [27] presented numerous commercial PCMbased solutions for LSF construction. In this study, five different examples of commercial PCM boards for dry construction, containing microencapsulated PCMs, can be consulted. Regarding macroencapsulated PCM, Santos et al. [28] presented three different solutions: ceiling tiles with a honeycomb core filled with PCM; aluminum-laminated panel containing a PCM that can be used after the plasterboard layer; and suspended ceiling tiles with PCM bags placed above.

Figueiredo et al. [4] performed an optimization study toward overheating reduction for buildings with low thermal inertia subjected to a Mediterranean climate. The authors attained a reduction of overheating risk by up to $24 \%$ in the cooling season, due to the optimization of the following parameters: ventilation rate; PCM melting temperate range; PCM position into construction solutions; and combining different melting temperatures in the same construction solution. The authors highlighted that the complete charge-discharge cycle of the PCM on a daily basis is only possible considering an effective compromise with the PCM melting temperature and ventilation rate selection.

These studies have paved the way to confirm that the use of PCMs as a second skin of the insulation layer substantially improves the building's thermal performance. However, we identified a literature gap regarding the type of PCM, such as salt hydrates due to their lower cost and form of macroencapsulation in building components, despite its huge potential for reduction in buildings' energy demand. Hence, the development and the thermal characterization of a thermally enhanced construction solution containing a salt hydrate PCM is proposed, suitable for incorporating into lightweight construction assemblies. Additionally, the developed PCM enhanced solution is also adequate for use at the inner surface of existing buildings in retrofit scenarios, targeting the reduction in internal overheating whilst promoting indoor passive thermal regulation, especially in warm climate conditions.

\section{Materials and Methods}

Previously, a numerical parametric simulation was carried out to support the PCM melting range for experimental development of the building solution with a thermally activated core. An experimental campaign to determine the thermal properties of a thermally enhanced solution based on a lightweight cold-formed steel solution containing macroencapsulated PCMs was performed, used in the scope of a comparison between two twin full-scale tiny houses located at the University of Aveiro campus (Portugal). The thermal characterization of the solution was performed in three phases:

(i) Characterize the acquired PCM (RUBITHERM SP21E-manufacturer product reference) enthalpy-temperature curves by means of differential scanning calorimetry (DSC) analysis;

(ii) Determine the equivalent thermal conductivity of the thermally active core solution (with PCM layer) and its comparison to a reference solution (without PCM), through the hot box heat flux meter method in steady state conditions;

(iii) Analyze indoor temperature behavior in free floating conditions (passive chamber) as consequence of a controlled induced temperature (active chamber), using the hot box apparatus.

The methodology of the present work begins with the case study definition regarding the two tiny houses that will be used for a future real-scale evaluation of the indoor thermal comfort conditions comprising the lightweight external envelope solutions. The second step of this work was developed, resourcing a dynamic simulation, using the EnergyPlus ${ }^{\mathrm{TM}}$ software. This step aims to define the adequate PCM melting temperature range to be applied in the construction solution, by changing the PCM operational temperature range according to the manufacturer options (commercial based solutions with different melting temperatures and enthalpy). From the parametric study resulted the selection over a 
commercially available PCM from RUBITHERM with reference SP21E. This PCM consists of a product based on salt-water mixtures and additives and it was macroencapsulated into aluminum cases with dimensions of $450 \mathrm{~m} \times 300 \mathrm{~m} \times 15 \mathrm{~m}$, thus containing approximately $2 \mathrm{~kg}$ of pure PCM per macrocapsule. Macrocapsules consist of two shaped aluminum plates attached to each other, forming a final thickness of $15 \mathrm{~mm}$ (aluminum plates containing PCM). They are joined at two centerd points and joined together at their frames (see Figure 1). This macrocapsule, due to its composition based on aluminum, allow high heat transfer between the PCM and the materials in contact with the aluminum macrocapsule. This specific PCM solution was selected instead of a conventional paraffinic PCM-based solution, due to the fact that the paraffinic PCMs reveal relatively low ignition resistance. Thus, and compared to the generic paraffinic solutions, salt hydrate based PCMs are not flammable and therefore highly recommended for construction solution incorporation.

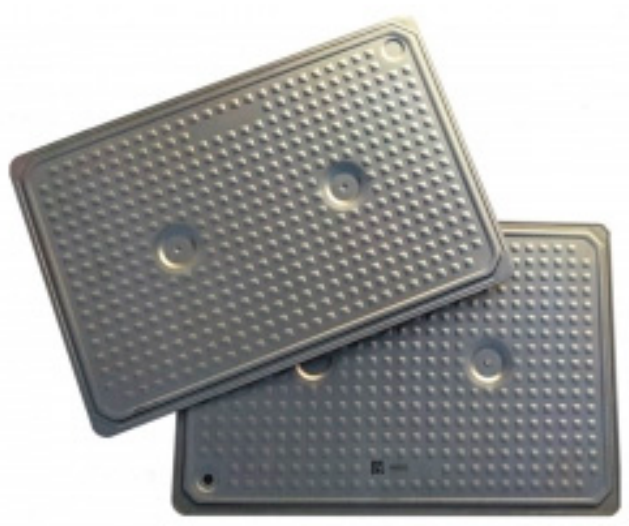

Figure 1. PCM encapsulated in aluminum container.

The main manufacturers' characteristics of the selected PCM are listed in Table 1.

Table 1. PCM properties used in this research (technical data from the manufacturer).

\begin{tabular}{cccccc}
\hline $\begin{array}{c}\text { Designation from } \\
\text { Manufacturer }\end{array}$ & Product Material & $\begin{array}{c}\text { Melting } \\
\text { Temperature/ } /{ }^{\circ} \mathbf{C} \\
\text { Range }\end{array}$ & $\begin{array}{c}\text { Crystallization } \\
\text { Temperature/ }{ }^{\circ} \mathbf{C} \\
\text { Range }\end{array}$ & $\begin{array}{c}\text { Latent Heat } \\
\text { Capacity/kJ kg } \mathbf{~ s}^{-\mathbf{1}}\end{array}$ & $\begin{array}{c}\text { Thermal Conductivity/W } \\
\mathbf{m}^{-\mathbf{1}}{ }^{\circ} \mathbf{C}^{-\mathbf{1}}\end{array}$ \\
\hline SP21E & $\begin{array}{c}\text { Salt-water mixtures } \\
\text { and additives }\end{array}$ & $22-23$ & $21-19$ & 170 & 0.50 \\
\hline
\end{tabular}

Finally, as a third step, two building solutions of the representative external envelope walls (reference solution without PCM and thermally enhanced solution with PCM) were thermally characterized in laboratory conditions and compared.

\section{Case Study Definition}

\subsection{Tiny Houses_-Real Scale Case Study}

The present case study is depicted in Figure 2, consisting of two lightweight buildings with a cold-formed steel assembly, commonly designated as a light steel frame (LSF) structure, with a treated floor area of $35 \mathrm{~m}^{2}$, which corresponds to a volume of $125 \mathrm{~m}^{3}$. A building with this area, geometry and construction system is considered representative of a typical tiny house that is easily erected in densely constructed urban areas. This construction technology was chosen for the two tiny houses due to the growing tendency for prefabricated construction systems, the faster building technology and the current trend of residential downsizing and changing ownership/use. The LSF construction technology offers a significant cost reduction potential, allowing, at the same time, improved quality control due to the nature of the structure assembly. However, as previously stated, this building technology presents low thermal inertia and a significant risk of overheating as its major weaknesses. Therefore, there is a need to improve the building construction technology with the use of functionalized materials to define advanced building solutions to overcome its inherent reduced thermal inertia. 


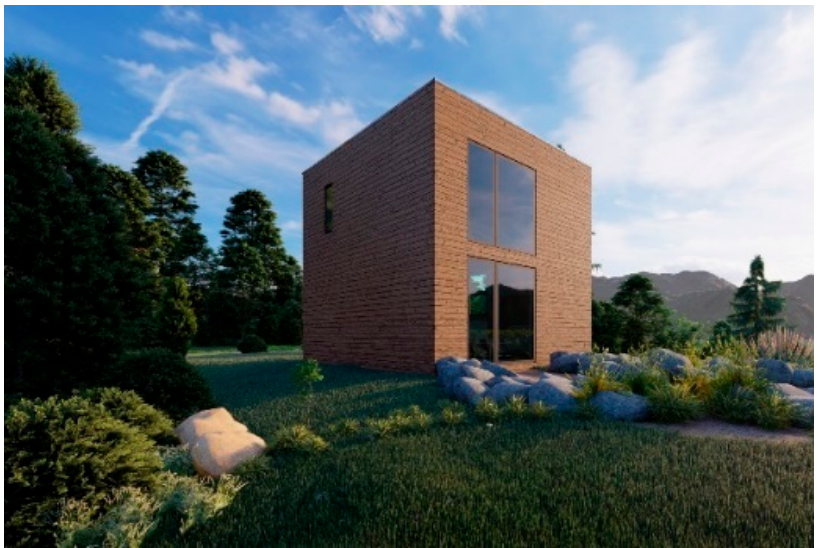

(a)

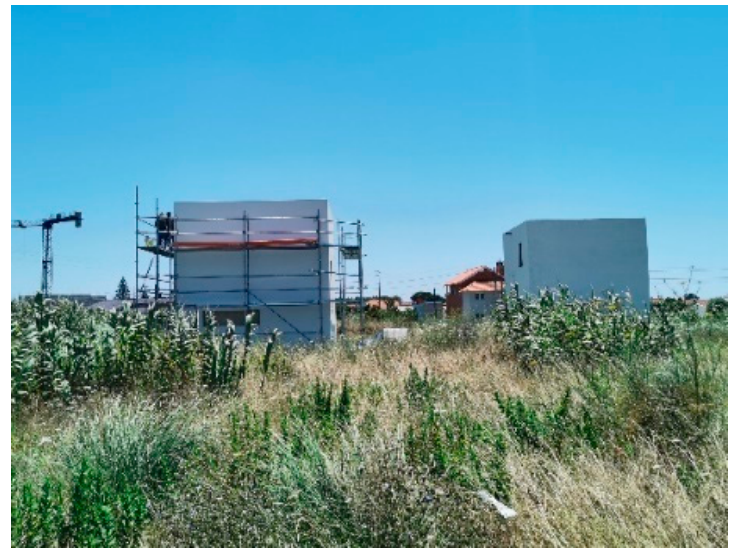

(b)

Figure 2. Tiny houses case study: (a) 3D design view of the tiny houses; (b) tiny houses under construction.

As observed in Figure 2, the largest glazed surfaces are southwest-oriented to potentiate the solar heat gains. However, for the sake of comparison and attaining reliable results, no shading solutions and/or systems were used in this phase to prevent overheating in the warm season, thereby expecting a higher risk of overheating during the summer season.

For this study, one of the external envelopes (walls and roof) of the tiny houses was constructed with the standard solutions to act as the reference cell, while the other tiny house was executed comprising the thermally enhanced core solution in order to be compared to the reference cell in terms of indoor thermal behavior.

\subsection{Construction Solutions of the Reference Tiny House}

The building's envelope walls, floor and roof are composed of LSF structural elements, with the thermal insulation layer installed on the exterior surface. In Table 2 are listed the characteristics of the insulation thickness and the thermal transmission coefficient ( $U$-values) of the adopted construction solutions for the ground floor level, facade walls, and roofing system, namely, the insulation thickness and $U$-value of the envelope construction solutions.

Table 2. Insulation thickness and $U$-value of the envelope construction solutions.

\begin{tabular}{|c|c|c|}
\hline $\begin{array}{c}\text { Opaque Construction } \\
\text { Element }\end{array}$ & $\begin{array}{l}\text { Mineral Wool }{ }^{*} \text { Insulation } \\
\text { Thickness }(\mathrm{mm})\end{array}$ & $U$-Value $\left(\mathrm{W} \mathrm{m}^{-2}{ }^{\circ} \mathrm{C}^{-1}\right)$ \\
\hline Ground floor slab & 60 & 0.54 \\
\hline Façade walls & 60 & 0.47 \\
\hline Flat roof & 40 & 0.63 \\
\hline
\end{tabular}

* Thermal conductivity of $0.037 \mathrm{~W} \mathrm{~m}^{-1}{ }^{\circ} \mathrm{C}^{-1}$.

Focusing on the external envelope walls, Figure 3 presents the standard construction solution, applied in the reference tiny house. The ground floor and the roof assembly solutions are equivalent in terms of material layers (although with different thicknesses). The wall construction solution test specimen presented in Figure 3 have dimensions of $800 \times 650 \times 190 \mathrm{~mm}^{3}$.

With respect to the glazed envelope, the windows are composed of aluminum frames $\left(U_{\text {Frame }}=2.40 \mathrm{~W} \mathrm{~m}^{-2}{ }^{\circ} \mathrm{C}^{-1}\right)$ with double glazing $\left(U_{\text {Glass }}=1.00 \mathrm{~W} \mathrm{~m}^{-2}{ }^{\circ} \mathrm{C}^{-1}\right)$ and a solar heat gain coefficient of 0.21 . This solution consists of a $6 \mathrm{~mm}$ thick exterior glazing pane, a $16 \mathrm{~mm}$ wide argon gas filled space, and a second laminated glazing pane of $8.76 \mathrm{~mm}$. 


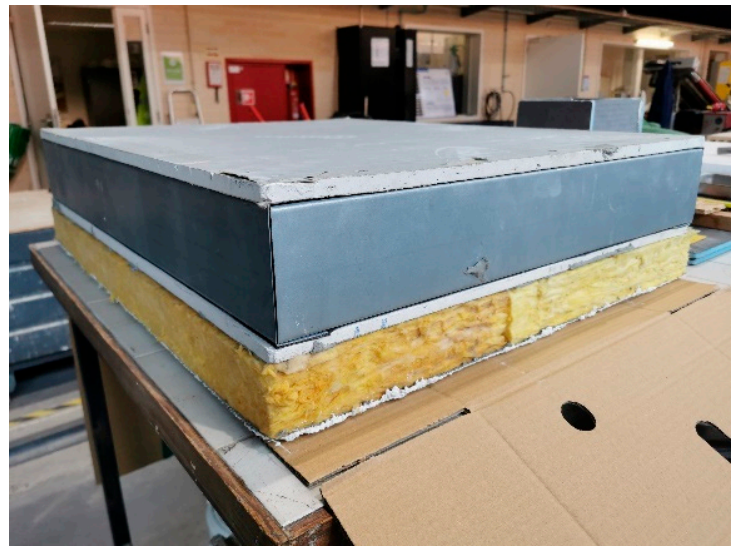

(a)

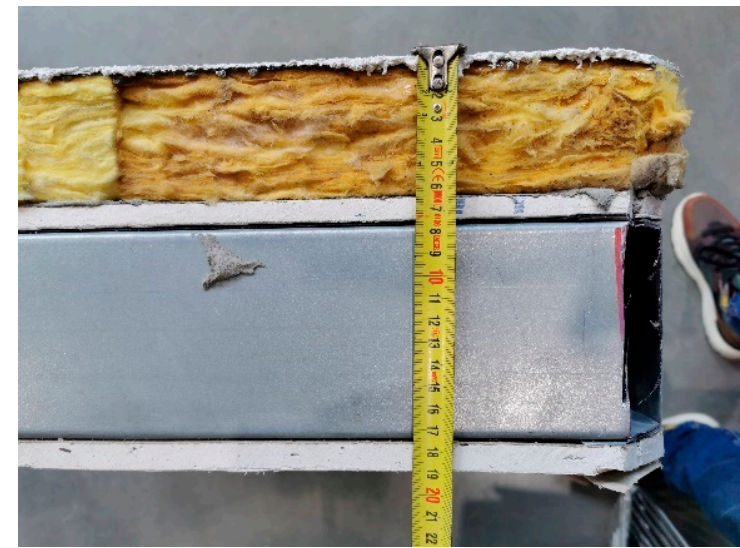

(b)

Exterior

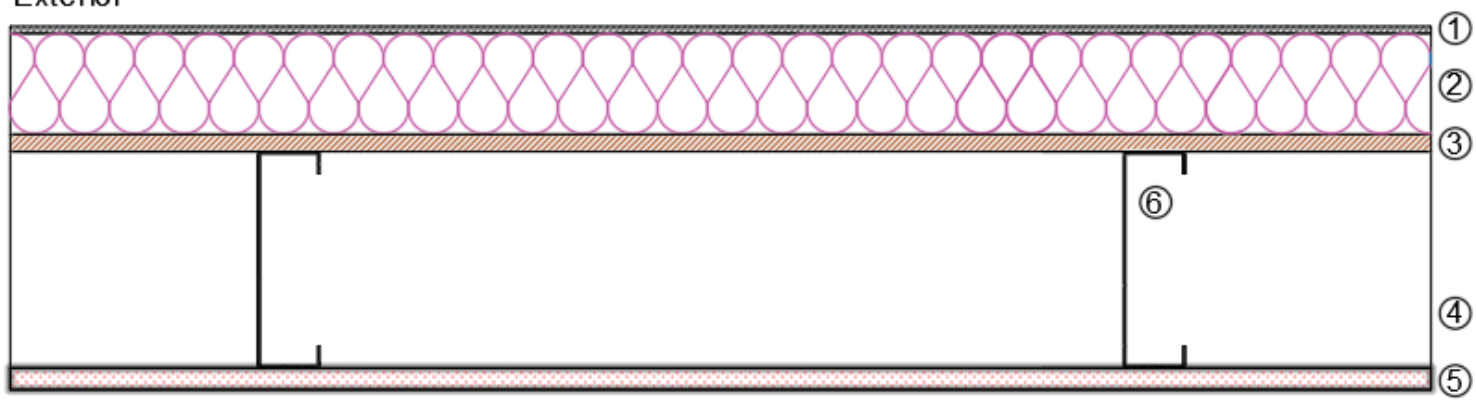

Interior

(1)—Finishing plaster / $5 \mathrm{~mm}$
(2)—Mineral wool / $60 \mathrm{~mm}$
(3)—Glass fiber reinforced gypsum board / $12.5 \mathrm{~mm}$
(4)—Cir gap / $100 \mathrm{~mm}$
(5)—Gypsum plasterboard / $12.5 \mathrm{~mm}$
(6)—Cold-formed C section

(c)

Figure 3. Construction solution of the envelope walls: (a) 3D view of wall component; (b) cross section view of the wall component; (c) layered composition of the reference solution.

\subsection{Construction Solutions with Active Core-PCM Macrocapsule}

Based on the reference envelope wall, an enhanced construction solution is presented in this section. This solution as well as the PCM macrocapsule core position within it, are defined based on experience from studies developed by the authors [4]. In these, an optimization process was performed, incorporating different PCM solutions (the PCM operating temperature range was defined based on dynamic simulation analysis (See Section 3.4)) as well as their position in the exterior envelope construction solution, targeting two objective functions: the reduction in the overheating rate and heating demand. In [4], it was concluded that the PCM charging and discharging process (phase change) is more effective when the PCM is positioned closest to the innermost layer of the construction solution. In this sense, as depicted in Figure 4, the same location was selected for the position of the PCM core, immediately behind the finishing layer of the gypsum plasterboard. 


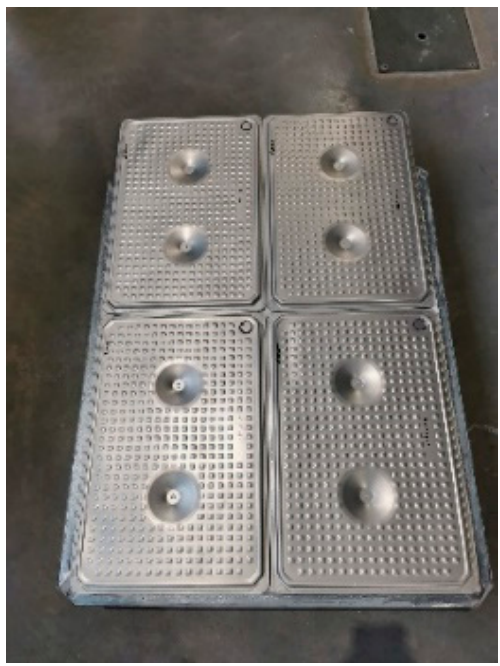

(a)

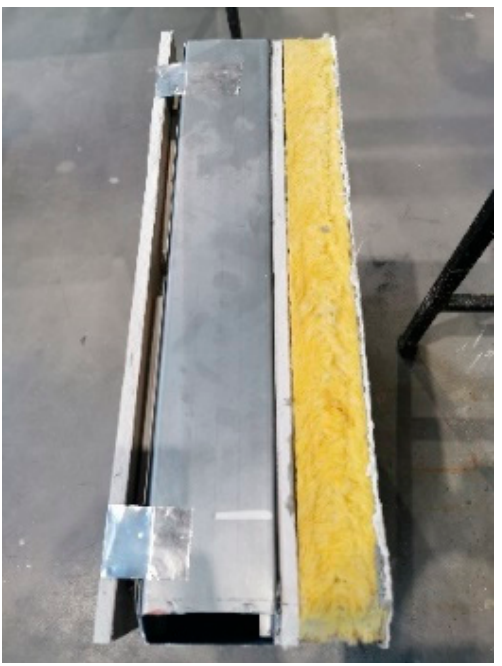

(b)

Exterior

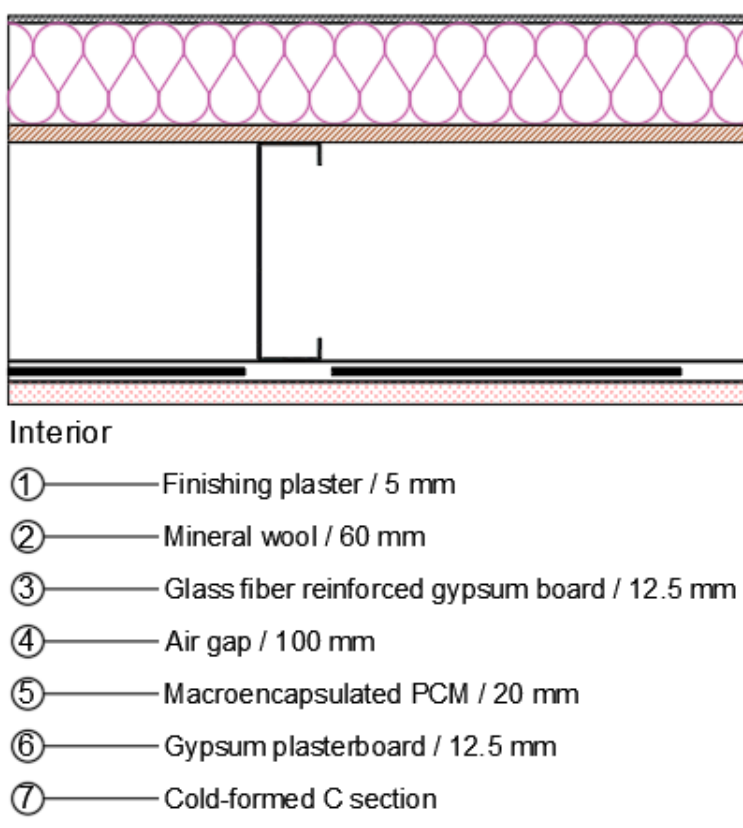

(c)

Figure 4. Construction solution of the envelope walls for the thermally enhanced tiny house (test cell): (a) macroencapsulated PCM with aluminum case; (b) cross section of the enhanced solution; (c) layered composition of the enhanced solution.

\subsection{Whole Building Dynamic Simulation}

This section presents the whole building dynamic simulation carried out to perform a parametric study to define the most adequate and effective trade-off between the PCM selection and the operating temperature range, to fully exploit the potential of the PCM charging and discharging process on a daily cycle. The use of enhanced solutions containing PCM requires a careful design of the construction solutions, starting from the selection of the PCMs' operating temperature range; otherwise, the full potential of the material latent heat may be underexplored, including the external boundary conditions and internal use profile (internal gains). Thus, to fulfil this purpose, the whole building dynamic simulation software EnergyPlus ${ }^{\mathrm{TM}}$ was used to numerically analyze the dynamic thermal behavior of the tiny house, comprising the enhanced solution with PCMs applied in the external envelope walls. Due to the use of PCMs in the present work, the conduction transfer 
function (CTF) model for the algorithm of surface heat balance calculation methodology was used. Regarding the thermal zones, the model has two thermal zones dividing the ground and the elevated floor areas (Figure 5).

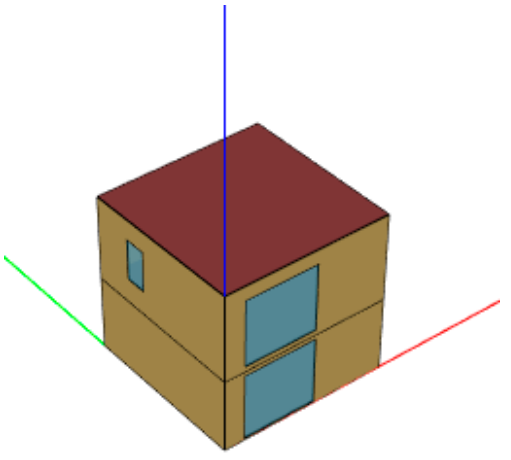

(a)

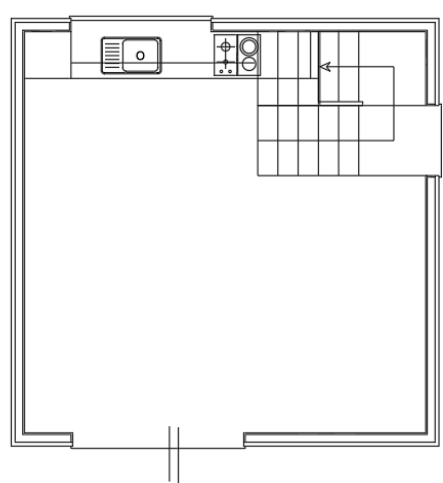

(b)

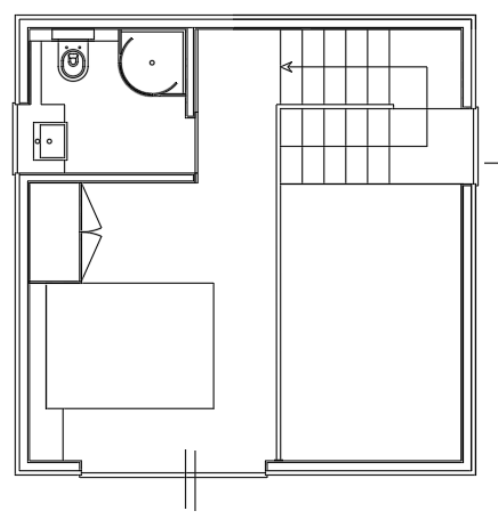

(c)

Figure 5. Numerical model design in EnergyPlus ${ }^{\mathrm{TM}}$ : (a) 3D model; $(\mathbf{b}, \mathbf{c})$ tiny house architectural blueprints (no scale).

Regarding the weather conditions, the case study is located in the Aveiro region, in the north central coastal region of Portugal, approximately $10 \mathrm{~km}$ from the Atlantic Ocean. Considering the Köppen-Geiger climate World Map classification for a simplified weather

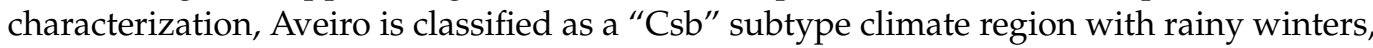
dry summers and an average air temperature in the warmest month of $22^{\circ} \mathrm{C}$.

\section{Results and Discussion}

\subsection{PCM Selection Using Dynamic Simulation}

As previously mentioned, the PCM operating temperature range was selected through numerical simulation of the building thermal behavior in free-running conditions. The expected thermal regulation effect of the PCM is to buffer the temperature fluctuation in the cooling season during the day to prevent overheating risk (indoor temperature above $25^{\circ} \mathrm{C}$ ). During the heating season, the effect of the PCM is expected to store heat during the day and release the absorbed thermal energy during the night period to avoid an excessive temperature drop of the indoor air temperature, thus balancing diurnal and nocturnal indoor temperatures in a passive manner.

Since overheating can be defined as the number of hours for which the indoor temperature is above $25^{\circ} \mathrm{C}$ on an annual analysis, according to Figure 6, it is possible to conclude that all analyzed possible PCM solutions are subjected to high overheating risk, highlighting longer periods for the reference scenario and for the scenario containing PCM with a peak melting temperature closest to the upper temperature limit for indoor thermal comfort, establishing overheating (indoor temperature above $25^{\circ} \mathrm{C}$ ). Furthermore, it is possible to conclude that the use of PCMs with high peak melting temperature can increase the risk of overheating, hindering indoor spaces to manage to decrease the indoor air temperature during the night period. Thus, the best result was attained for the construction solution with PCM SP21E, revealing a total of $4 \%$ of the year in thermal discomfort by overheating. 


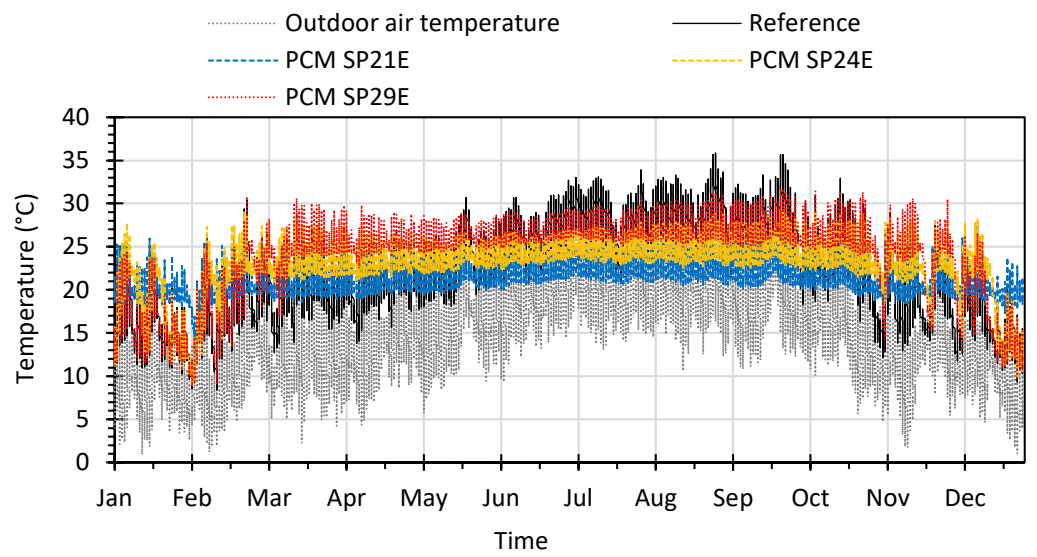

Overheating $\rightarrow$ Indoor temperature $>25^{\circ} \mathrm{C}$

Reference -3147 hours

PCM SP21E - 357 hours

PCM SP24E - 2271 hours

PCM SP29E - 5398 hours

Figure 6. Annual indoor air temperature results: reference model vs. model with thermally enhanced solutions comprising different PCM operating temperature ranges.

\subsection{PCM Thermal Characterization: Differential Scanning Calorimetry and T-History}

The relationship of enthalpy as a function of temperature is one of the most important thermal properties of PCMs, as it reveals the material thermal behavior in terms of phase change and latent heat capacity. Differential scanning calorimetry (DSC) analysis is a laboratory test in which the PCM samples are submitted to controlled temperatures for heating and cooling cycles at specific heating and cooling rates, and the corresponding heat fluxes are recorded, thus providing the relevant information about the temperatures and the associated specific enthalpies, according to the PCM's crystallization and melting processes. For obtaining the phase change temperature range as well as the enthalpy (or specific heat capacity) as a function of temperature, DSC tests were performed on the pure sample of Rubitherm PCM SP21E. Before testing, due to the hygroscopic properties of this PCM solution, the samples were frozen at $0{ }^{\circ} \mathrm{C}$, according to the manufacturer recommendation. Then, the test was executed for heating and cooling cycles within a temperature range comprehended between 10 and $50{ }^{\circ} \mathrm{C}$ at the heating and cooling rates of $1{ }^{\circ} \mathrm{C} \mathrm{min}{ }^{-1}$, and the weight of the PCM samples was approximately $32.15 \mathrm{mg}$. The experimental results obtained are presented in Figure 7 for the heating and cooling cycles, respectively.

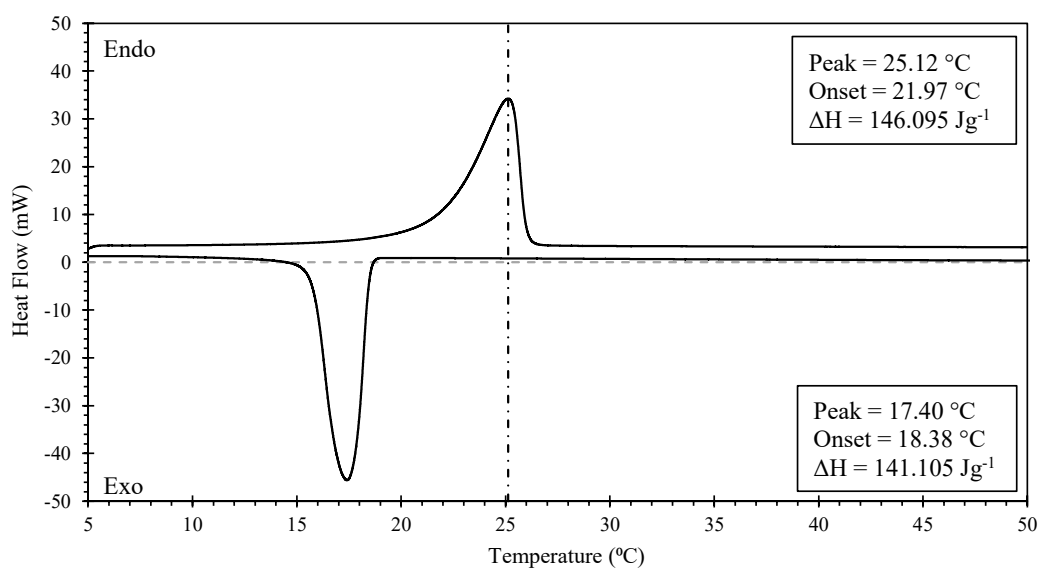

Figure 7. DSC curves for the pure samples of the Rubitherm PCM SP21E.

Regarding Figure 7, a difference between the peak melting and peak crystallization temperatures was observed, thus revealing the existence of a supercooling phenomenon (around $7.72{ }^{\circ} \mathrm{C}$ of supercooling). Regarding the manufacturer technical data, the expected peak melting temperature should occur at $21^{\circ} \mathrm{C}$; however, during the melting phase of the PCM, a peak melting temperature of $25.12{ }^{\circ} \mathrm{C}$ was attained. During the crystallization phase, the peak crystallization was attained for a temperature value of $17.40^{\circ} \mathrm{C}$. 
Given the attained differences in terms of expected (technical datasheet) and experimentally obtained (DSC) peak melting temperatures, a new test was executed using the T-history approach, as presented in Figure 8.
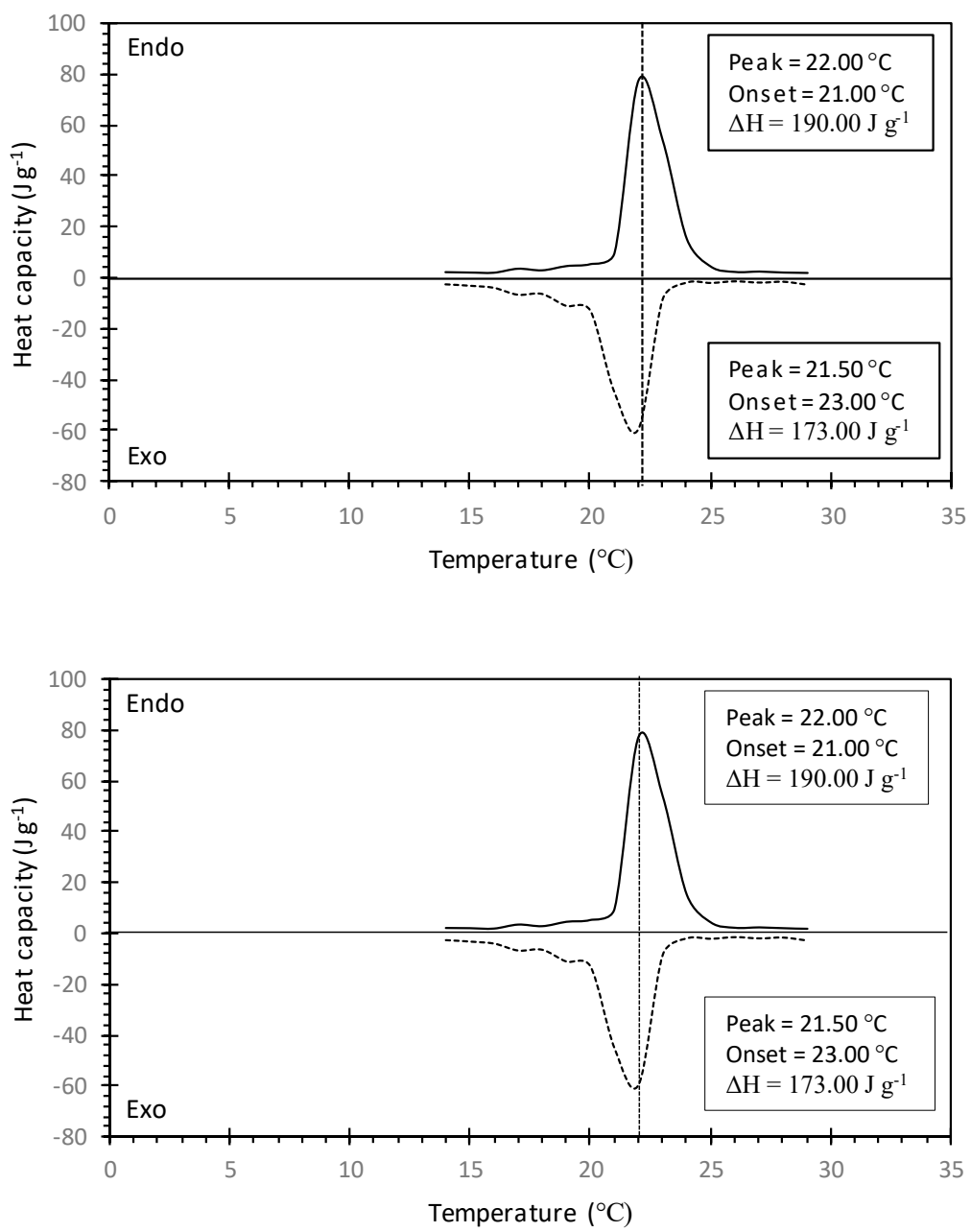

Figure 8. T-history analysis to measure enthalpy for the pure PCM SP21E.

In this test methodology, pure PCM samples with approximately $15 \mathrm{gr}$ of weight were heated up to $60^{\circ} \mathrm{C}$ in a water bath until completely melted and then cooled down to $10{ }^{\circ} \mathrm{C}$ to find the supercooling degree.

Comparing the DSC curves with the T-history test, changes in thermal behavior were registered regarding the peak melting temperatures, onset temperature values and enthalpy, despite the fact that the PCM tested was exactly the same product, collected from the same batch.

The differences observed for the results may be related to the total amount of the sample tested (and how it was collected) for the two approaches. Despite DSC analysis being a standard tool for the measurement of latent heat of PCMs, this specific method requires a very reduced material sample. This characteristic may not be problematic with homogeneous materials. Nevertheless, salt hydrate PCMs present local heterogeneities, which may induce sampling errors to the DSC tests, thus not allowing to be obtained the representative properties of the compound [29-31]. The T-history method proved to be more suitable for salt hydrate based PCMs.

\subsection{Hot Box Heat Flux Meter}

To evaluate the impact of incorporating the PCMs into the construction solution of the external envelope walls in terms of equivalent thermal conductivity, the hot box heat 
flux meter approach was used. The hot box apparatus consists of two chambers with controlled conditions of temperature and relative humidity, separated by a mounting ring where the test specimen is installed. This test was developed to evaluate the equivalent thermal conductivity of the representative wall specimens, from the base wall solution (reference wall) to the developed solution containing the PCM macrocapsules (enhanced solution). As previously referred, the enhanced wall solution comprises an inner layer (located behind the gypsum plaster wallboard) containing the aluminum macrocapsules of PCM. Both specimens were instrumented with heat flux meters on both sides (HTflux), with PT100 sensors inside the chambers (Figure 9).

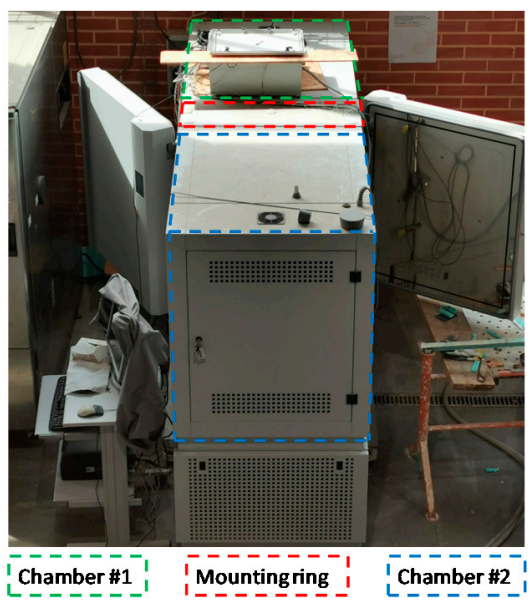

(a)

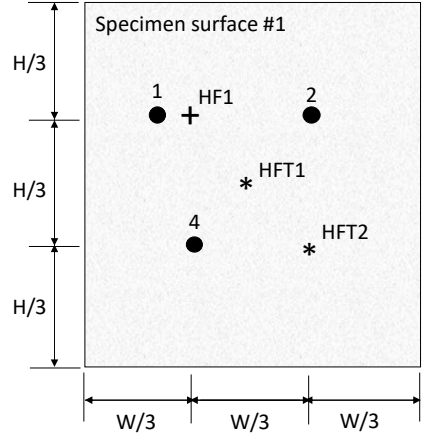

- Thermocouple + Heat flux meter

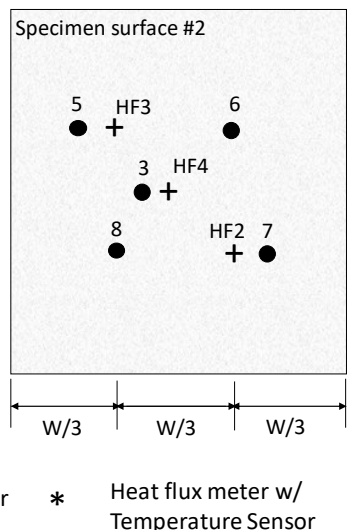

(b)

Figure 9. Hot box heat flux meter approach: (a) hot box apparatus (b) schematic layout of heat flux meter and temperature sensors positioning on the specimens' surfaces.

The first test was conducted with the goal of characterizing the equivalent thermal conductivity of the reference wall, followed by the enhanced wall containing PCM macrocapsules. Thus, in Figure 9, it is presented the experimental results of the heat fluxes as a function of the temperature increase in steps of steady state conditions. For both wall specimens, 17 steady state steps were defined.

Analyzing the results from Figure 10 , a value of $0.13 \mathrm{~W} \mathrm{~m}^{-1}{ }^{\circ} \mathrm{C}^{-1}$ was obtained for the thermal conductivity (at a temperature step of $22^{\circ} \mathrm{C}$ ) as a function of the mean specimen temperature for the reference wall, and a value of $0.12 \mathrm{~W} \mathrm{~m}^{-1}{ }^{\circ} \mathrm{C}^{-1}$ for the enhanced wall was also obtained for the equal temperature step.

Due to the observed variance in the heat flow as a function of the temperature evolution, specially highlighted in the case of the construction solution containing PCM, a full characterization regarding the thermal conductivity as a function of the mean specimen temperature for both wall solutions is presented in Figure 11.

The obtained results for thermal conductivity exhibited an increasing trend with an excellent correlation between the thermal conductivity values and the mean specimen temperatures, as corroborated by the square correlation coefficient $\left(\mathrm{R}^{2}\right)$ attained of 0.98 , for the reference wall solution. Thus, the performed test on the reference solution to attain the thermal conductivity evolution along the temperature increase resulted in a thermal conductivity comprehended between 0.08 and $0.33 \mathrm{~W} \mathrm{~m}-1{ }^{\circ} \mathrm{C}^{-1}$ for a temperature range between 14.87 and $42.55^{\circ} \mathrm{C}$.

For the enhanced wall solution with PCM macrocapsules, it was observed that during the phase change transition zone (assigned in the plot with a gray box), thermal conductivity values tend to maintain stability, followed by a slight decrease, thus revealing significant discrepancies in this parameter. This behavior occurs due to the simultaneous influence of temperature rise and phase change fraction of the PCM, in addition to the coexistence of two physical states with different thermophysical properties, evidencing the PCM's inherently 
non-linear nature [32]. The evaluated thermal conductivity values are comprehended between 0.08 and $0.11 \mathrm{~W} \mathrm{~m}^{-1}{ }^{\circ} \mathrm{C}^{-1}$ for temperature intervals from 15.04 to $19.00{ }^{\circ} \mathrm{C}$ below the phase change transition range, and thermal conductivity values above the phase change transition range are comprehended between 0.12 and $0.28 \mathrm{~W} \mathrm{~m}^{-1}{ }^{\circ} \mathrm{C}^{-1}$ for mean specimen temperatures of 26.79 to $42.58{ }^{\circ} \mathrm{C}$, respectively. The obtained results for both stages (before and after the phase change range) reveals an excellent $R^{2}$, demonstrating an excellent fit to the experimental data.

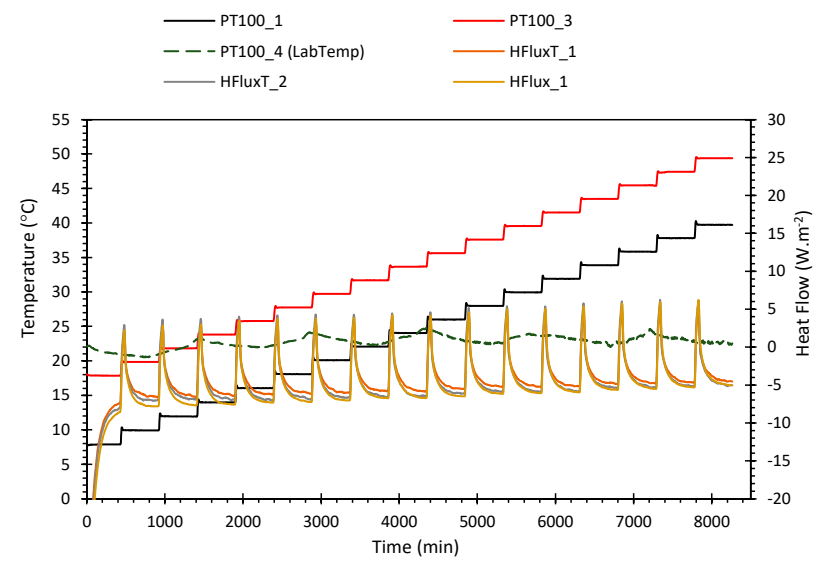

(a)

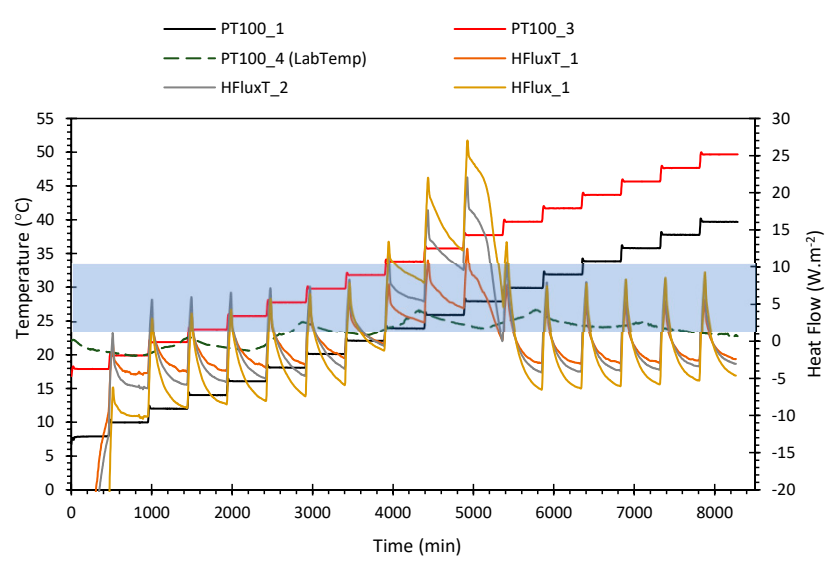

(b)

Figure 10. Hot box results: heat flux evolution when wall specimens are subjected to different temperature steps. (a) Reference construction solution; (b) enhanced construction solution with PCM macrocapsules.

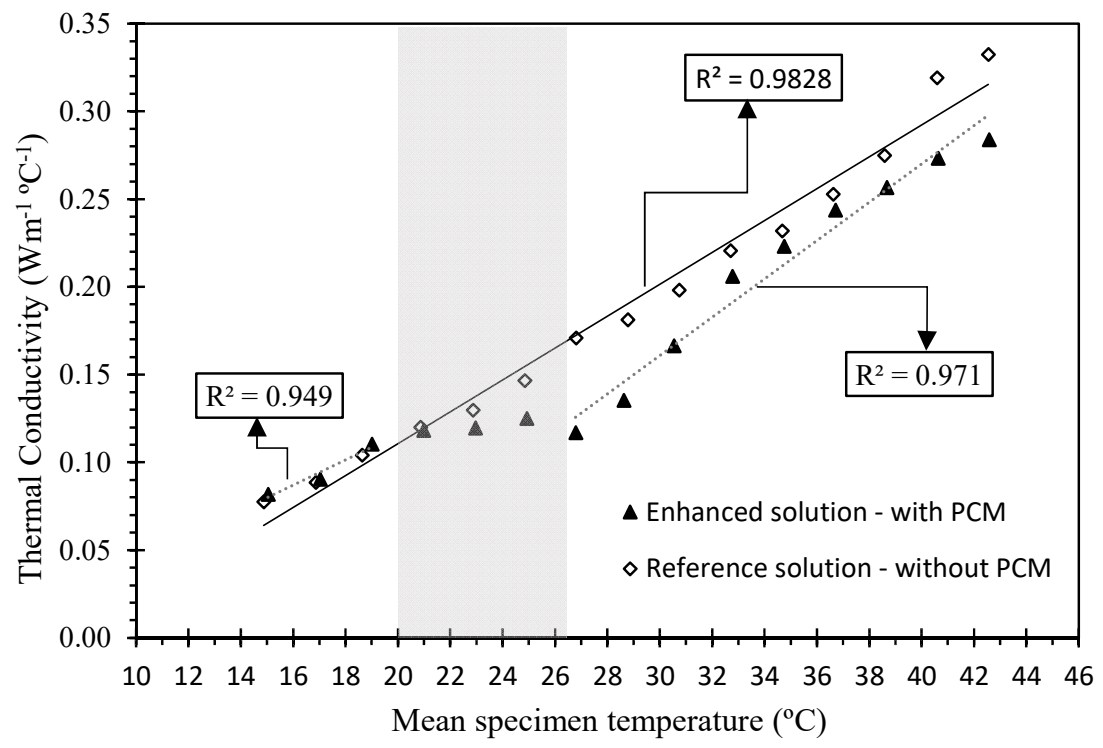

Figure 11. Equivalent thermal conductivity as function of the mean specimen temperature for both construction solutions.

Additionally, with the objective of comparing the thermal behavior of both wall solutions (the reference and the enhanced solution) when subjected to a temperature differential, simulating the indoor and outdoor temperature evolution of a daily cycle, the hot box apparatus was again used. Thus, the indoor temperature behavior was characterized in free-running conditions (using one chamber in passive conditions) as a consequence of a controlled temperature (using the other chamber in active metering mode).

Comparing the air temperature values inside the passive chamber (simulating indoor conditions) of both solutions, in Figure 12, a very expressive reduction in the temperature 
fluctuation was observed for the enhanced wall with PCM macrocapsules. A difference of $4{ }^{\circ} \mathrm{C}$ between curves was obtained for the period of the day in which we attained the maximum daily temperature inside the passive chamber. However, the fluctuation reduction presented in the temperature evolution curve of the construction solution containing PCM (red curve), observed after completing a cycle of $24 \mathrm{~h}$, is an indicator that the latent heat of the PCM will not be fully discharged considering a daily cycle. This behavior is observed by the reduction in the temperature difference between curves during the third cycle of the test (hours: 60 to 75 ).

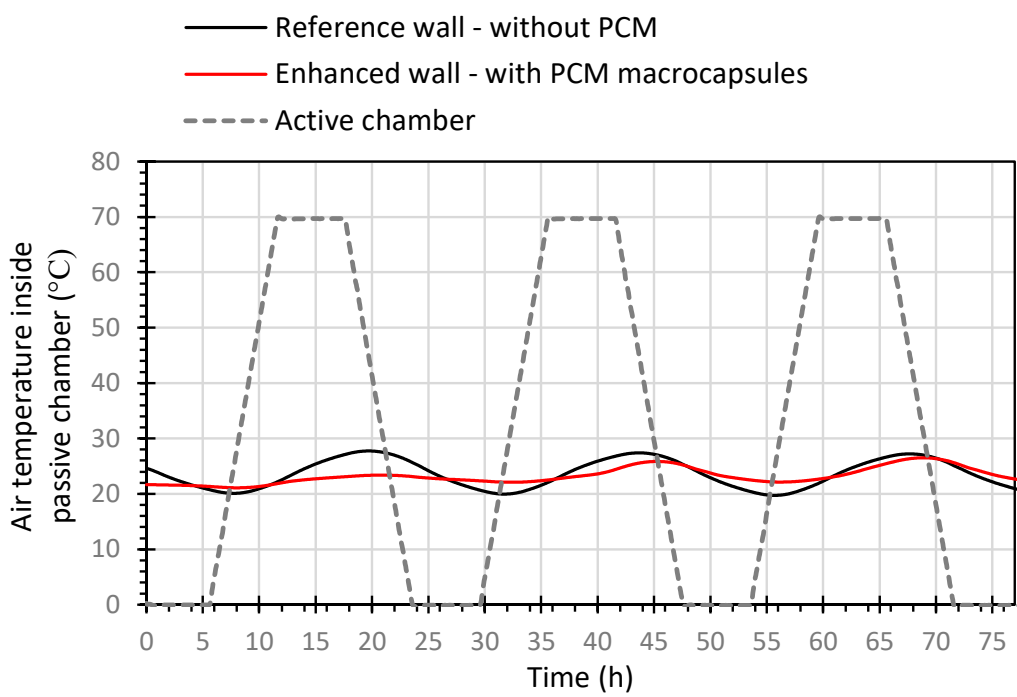

Figure 12. Hot box results: indoor air temperature profiles.

Analyzing the differences obtained between temperature curves, experimentally assessed, it is concluded that the use of PCM as a thermal regulator in the tiny houses certainly will contribute to the indoor thermal comfort in both seasons along the year with promising results.

\section{Conclusions}

The present study provides a meaningful contribution for passive thermal regulation strategies for indoor spaces, using a lightweight construction solution containing macroencapsulated salt hydrate based PCM. DSC and t-history analysis were used to characterize the thermal behavior of the PCM, and the hot box tests were used for thermal conductivity characterization of the construction solutions.

DSC analysis allowed the observation of several differences in the PCM thermophysical properties when compared with the manufacturer's datasheet. The T-history analysis revealed an increased accuracy of the latent heat behavior when compared with the manufacturer's datasheet rather than DSC. The T-history method proved to be more suitable for non-pure substances as well as for salt hydrate based PCMs. Thermophysical characterization revealed by the experimentally obtained heat storage capacity of $190 \mathrm{~J} \mathrm{~g}^{-1}$ allows to classify the use of salt hydrate PCMs as a possible alternative solution to the usual paraffinic-based PCMs.

Using the hot box approach, a good correlation between the equivalent thermal conductivity values and mean specimen temperatures was attained for the reference construction solution (without PCM) and for the enhanced construction solution containing PCM, when the mean specimen temperature is located outside the phase change transition zone (PCM completely solid and completely liquid). Thermal conductivity values tend to maintain stability during the phase change temperatures range, followed by a considerable decrease, thus revealing a non-linear behavior. Comparing the obtained values for thermal conductivity of both solutions, a reduction of $12.6 \%$ (average value) was observed 
in this thermal property, due to the addition of the PCM macrocapsules in the reference constructive solution.

Concerning the hot box approach test, with only one active chamber and the other chamber in free-running conditions, to evaluate the thermal regulation effect of the PCM, good results in terms of mitigating overheating rate reduction were attained. This proves that the use of salt hydrate based (macroencapsulated) PCMs incorporated into the envelope walls in such a construction system is suitable to compensate for the lack of thermal inertia of lightweight construction typologies, such as LSF buildings. Nevertheless, the hot box test revealed the importance of adequately select the operating temperature range of the PCMs, as a function of the desired indoor temperature range. On the other hand, the weight of the PCM incorporated into the construction solution plays a significant role in the overall efficiency since the excessive weight of PCM may not be fully charged/discharged for a daily cycle, as observed with the hot box test.

This study highlights the high potential for the development of innovative construction solutions incorporating salt hydrate based PCM macrocapsules, suitable to be incorporated into lightweight constructions toward new and existing buildings.

Author Contributions: All the authors have contributed to multiple tasks throughout this research. Conceptualization, A.F., A.S. and R.V.; methodology, A.F., A.S., J.L., F.R. and R.V.; validation, A.F. and F.R.; formal analysis, A.F., A.S., J.L., F.R. and R.V.; investigation, A.F., A.S., F.R. and R.V.; resources, A.F., J.L.; data curation, A.F., F.R. and R.V.; writing-original draft preparation, A.F. and F.R.; writing -review and editing, A.F., A.S., J.L., F.R. and R.V.; visualization, A.S. and R.V.; supervision, A.S. and R.V.; project administration, A.S.; funding acquisition, A.S. All authors have read and agreed to the published version of the manuscript.

Funding: This research was funded by the project THERMACORE-Performance of a wall or slab with a thermally active core in buildings in Portugal, POCI-01-0145-FEDER-030364, with the financial support of FCT-Fundação para a Ciência e Tecnologia/MCTES and was also supported by the Foundation for Science and Technology (FCT)-Aveiro Research Centre for Risks and Sustainability in Construction (RISCO), Universidade de Aveiro, Portugal [FCT/UIDB/ECI/04450/2020].

Institutional Review Board Statement: Not applicable.

Informed Consent Statement: Not applicable (study not involving humans).

Data Availability Statement: Not applicable.

Conflicts of Interest: The authors declare no conflict of interest.

\section{References}

1. Soares, N.; Bastos, J.; Pereira, L.D.; Soares, A.; Amaral, A.R.; Asadi, E.; Rodrigues, E.; Lamas, F.B.; Monteiro, H.; Lopes, M.A.R.; et al. A review on current advances in the energy and environmental performance of buildings towards a more sustainable built environment. Renew. Sustain. Energy Rev. 2017, 77, 845-860. [CrossRef]

2. EPBD Directive 2018/844/EU. Directive 2018/844/EU of the European Parliament and of the Council of 30 May 2018. Off. J. Eur. Communities Union 2018, 19, 75-91.

3. De Almeida, A.; Fonseca, P.; Schlomann, B.; Feilberg, N. Characterization of the household electricity consumption in the EU, potential energy savings and specific policy recommendations. Energy Build. 2011, 43, 1884-1894. [CrossRef]

4. Figueiredo, A.; Vicente, R.; Oliveira, R.; Rodrigues, F.; Samagaio, A. Multiscale modelling approach targeting optimisation of pcm into constructive solutions for overheating mitigation in buildings. Appl. Sci. 2020, 10, 8009. [CrossRef]

5. Kishore, R.A.; Bianchi, M.V.A.; Booten, C.; Vidal, J.; Jackson, R. Parametric and sensitivity analysis of a PCM-integrated wall for optimal thermal load modulation in lightweight buildings. Appl. Therm. Eng. 2021, 187, 116568. [CrossRef]

6. Adilkhanova, I.; Memon, S.A.; Kim, J.; Sheriyev, A. A novel approach to investigate the thermal comfort of the lightweight relocatable building integrated with PCM in different climates of Kazakhstan during summertime. Energy 2021, $217,119390$. [CrossRef]

7. Salgueiro, T.; Samagaio, A.; Gonçalves, M.; Figueiredo, A.; Labrincha, J.; Silva, L. Incorporation of phase change materials in an expanded clay containing mortar for indoor thermal regulation of buildings. J. Energy Storage 2021, 36, 102385. [CrossRef]

8. Rebelo, F.; Figueiredo, A.; Vicente, R.; Ferreira, V.M. Study of a thermally enhanced mortar incorporating phase change materials for overheating reduction in buildings. J. Energy Storage 2022, 46, 103876. [CrossRef] 
9. Gencel, O.; Hekimoğlu, G.; Sarı, A.; Sutcu, M.; Er, Y.; Ustaoglu, A. A novel energy-effective and carbon-emission reducing mortars with bottom ash and phase change material: Physico-mechanical and thermal energy storage characteristics. J. Energy Storage 2021, 44, 103325. [CrossRef]

10. Saxena, R.; Ali, S.F.; Rakshit, D. PCM incorporated bricks: A passive alternative for thermal regulation and energy conservation in buildings for Indian conditions. In Eco-Efficient Materials for Reducing Cooling Needs in Buildings and Construction; Elsevier: Amsterdam, The Netherlands, 2021; pp. 303-328.

11. Al-Yasiri, Q.; Szabó, M. Thermal performance of concrete bricks based phase change material encapsulated by various aluminium containers: An experimental study under Iraqi hot climate conditions. J. Energy Storage 2021, 40, 102710. [CrossRef]

12. Bondareva, N.S.; Sheremet, M.A. Influence of phase change material melting point and its location on heat and mass transfer in a brick. J. Energy Storage 2021, 42, 103122. [CrossRef]

13. Millers, R.; Korjakins, A.; Lesinskis, A. Thermally activated concrete slabs with integrated PCM materials. E3S Web Conf. 2019, 111, 01080. [CrossRef]

14. Figueiredo, A.; Lapa, J.; Vicente, R.; Cardoso, C. Mechanical and thermal characterization of concrete with incorporation of microencapsulated PCM for applications in thermally activated slabs. Constr. Build. Mater. 2016, 112, 639-647. [CrossRef]

15. Maleki, B.; Khadang, A.; Maddah, H.; Alizadeh, M.; Kazemian, A.; Ali, H.M. Development and thermal performance of nanoencapsulated PCM/ plaster wallboard for thermal energy storage in buildings. J. Build. Eng. 2020, 32, 101727. [CrossRef]

16. Song, Y.; Li, C.; Yu, H.; Tang, Y.; Xia, Z. Optimization of the phase-change wallboard test method: Experimental and numerical investigation. J. Energy Storage 2020, 30, 101559. [CrossRef]

17. Li, C.; Yu, H.; Song, Y. Experimental investigation of thermal performance of microencapsulated PCM-contained wallboard by two measurement modes. Energy Build. 2019, 184, 34-43. [CrossRef]

18. Millers, R.; Korjakins, A.; Lešinskis, A.; Borodinecs, A. Cooling panel with integrated PCM layer: A verified simulation study. Energies 2020, 13, 5715. [CrossRef]

19. Devaux, P.; Farid, M.M. Benefits of PCM underfloor heating with PCM wallboards for space heating in winter. Appl. Energy 2017, 191, 593-602. [CrossRef]

20. Yun, B.Y.; Yang, S.; Cho, H.M.; Chang, S.J.; Kim, S. Design and analysis of phase change material based floor heating system for thermal energy storage. Environ. Res. 2019, 173, 480-488. [CrossRef]

21. Elarga, H.; Fantucci, S.; Serra, V.; Zecchin, R.; Benini, E. Experimental and numerical analyses on thermal performance of different typologies of PCMs integrated in the roof space. Energy Build. 2017, 150, 546-557. [CrossRef]

22. Sun, W.; Zhang, Y.; Ling, Z.; Fang, X.; Zhang, Z. Experimental investigation on the thermal performance of double-layer PCM radiant floor system containing two types of inorganic composite PCMs. Energy Build. 2020, 211, 109806. [CrossRef]

23. Kuznik, F.; David, D.; Johannes, K.; Roux, J.-J. A review on phase change materials integrated in building walls. Renew. Sustain. Energy Rev. 2011, 15, 379-391. [CrossRef]

24. Sun, W.; Zhang, Z.; Wu, Z.; Xu, Y. Numerical modeling and optimization of annual thermal characteristics of an office room with PCM active-passive coupling system. Energy Build. 2022, 254, 111629. [CrossRef]

25. Xu, X.; Zhang, Y.; Lin, K.; Di, H.; Yang, R. Modeling and simulation on the thermal performance of shape-stabilized phase change material floor used in passive solar buildings. Energy Build. 2005, 37, 1084-1091. [CrossRef]

26. Kośny, J.; Fallahi, A.; Shukla, N.; Kossecka, E.; Ahbari, R. Thermal load mitigation and passive cooling in residential attics containing PCM-enhanced insulations. Sol. Energy 2014, 108, 164-177. [CrossRef]

27. Soares, N.; Gaspar, A.R.; Santos, P.; Costa, J.J. Multi-dimensional optimization of the incorporation of PCM-drywalls in lightweight steel-framed residential buildings in different climates. Energy Build. 2014, 70, 411-421. [CrossRef]

28. Santos, P.; Simões da Silva, L.; Ungureanu, V. Energy Efficiemcy of Light-Weight Steel-Framed Buildings; European Convention for Constructional Steelwork (ECCS): Mem Martins, Portugal, 2012.

29. Peck, J.H.; Kim, J.J.; Kang, C.; Hong, H. A study of accurate latent heat measurement for a PCM with a low melting temperature using T-history method. Int. J. Refrig. 2006, 29, 1225-1232. [CrossRef]

30. Solé, A.; Miró, L.; Barreneche, C.; Martorell, I.; Cabeza, L.F. Review of the T-history method to determine thermophysical properties of phase change materials (PCM). Renew. Sustain. Energy Rev. 2013, 26, 425-436. [CrossRef]

31. Mazo, J.; Delgado, M.; Lázaro, A.; Dolado, P.; Peñalosa, C.; Marín, J.M.M.; Zalba, B.; D'Avignon, K.; Kummert, M.; Lázaro, A.; et al Verification of a T-history installation to measure enthalpy versus temperature curves of phase change materials. Meas. Sci. Technol. 2016, 17, 2168-2174.

32. Amaral, C.; Vicente, R.; Eisenblätter, J.; Marques, P.A.A.P. Thermal characterization of polyurethane foams with phase change material. Ciência Tecnol. Mater. 2017, 29, 1-7. [CrossRef] 